\title{
ENTRAR NO ESCRITO NA IDADE ADULTA: \\ POR UMA ABORDAGEM SITUADA DO ENSINO DA \\ LEITURA E DA ESCRITA 1
}

\author{
Malory Leclère \\ malory.leclere@univ-paris3.fr \\ Universidade Sorbonne Nouvelle \\ Laurence Le Ferrec \\ laurence.le-ferrec@parisdescartes.fr \\ Universidade Paris Descartes
}

RESUMO: Face às necessidades de formação dos formadores e à grande heterogeneidade das práticas de ensino da leitura-escrita direcionadas aos adultos, esse artigo visa a estabelecer as bases de uma abordagem que não dissocie as aprendizagens formais da escrita das experiências da escrituralidade vivenciadas pelos aprendizes e representações que lhes são atribuídas. Após retomar componentes e etapas do processo de aprendizagem da língua escrita, o artigo propõe uma reflexão sobre procedimentos de ensino que se distanciam de uma concepção demasiadamente restritiva da língua escrita e que marcam uma ruptura com abordagens postas em prática com as crianças. Trata-se de procedimentos que integram a aprendizagem da escrita em um trabalho mais amplo sobre o desenvolvimento das competências sociocomunicacionais e consideram as representações dos aprendizes sobre o funcionamento, os usos e as funções da língua escrita.

PALAVRAS-CHAVE: leitura-escrita; formação de adultos; representações da escrita.

\section{LEARNING TO WRITE AT A MATURE AGE: TOWARDS A SITUATED APPROACH TO READING AND WRITING}

ABSTRACT: The training requirements of teachers and the broad heterogeneity of practices, when reading and writing are concerned, have led the authors to try and define the initial lines of an approach in which the formal teaching of writing is not dissociated from the learners' personal experience of literacy and its products. The components and the stages of the writing process will be described initially. This will be followed by a reflection on teaching practices which go beyond an overly restrictive conception of what the written language is. This reflection actually breaks with traditional approaches of teaching children how to write: learning how to write becomes part of the larger development of socio-communicative competencies. The learners' representations of how the written language operates, how it is used and what it is used for are taken into account.

KEYWORDS: reading-writing; adult education; representations on writing.

\footnotetext{
${ }^{1}$ Tradução do artigo "Entrer dans l'écrit à l'âge adulte : pour une approche située de l'enseignement de la lecture et de l'écriture", inédito, por Márcia Romero (UNIFESP) e Thatiana Ribeiro Vilela (PG-UNIFESP).
} 
Partimos, neste artigo, da constatação empírica de que existe, de um lado, uma extrema heterogeneidade de práticas de ensino da leitura-escrita no seio dos dispositivos de formação destinados aos adultos e, de outro, ao menos na França, uma grande necessidade de formação em um setor que, durante muito tempo, tendo contado com voluntários, profissionaliza-se cada vez mais, sobretudo graças às políticas de integração linguística, social e de formação profissional.

Nesse contexto, o objetivo de nossa contribuição é o de estabelecer as bases de uma abordagem situada da leitura-escrita na formação de adultos, uma abordagem que não dissocie as aprendizagens formais da escrita das experiências da escrituralidade vivenciadas pelos aprendizes e representações que lhes são atribuídas. Fundamentandonos em nossos trabalhos de pesquisa e nossas experiências como formadoras de formadores, e, mais ainda, nos trabalhos relacionados ao ensino-aprendizagem da escrita desenvolvidos em diferentes campos de pesquisa (linguística, didática das línguas, ciências cognitivas, antropologia e sociologia), buscamos mostrar sua pertinência e complementariedade para a implementação de procedimentos de ensino que, distanciando-se de uma concepção demasiadamente restritiva da língua escrita, integram sua aprendizagem em um trabalho mais amplo sobre o desenvolvimento das competências comunicacionais. Com efeito, as pessoas às quais esse tipo de formação se destina, mesmo se elas se caracterizam por uma enorme heterogeneidade (idade, percursos escolares ${ }^{2}$, perfil sociolinguístico, competências linguageiras ou profissionais), têm em comum a necessidade de desenvolver suas competências em leitura e escrita para conseguirem realizar, em situações sociais de diferentes naturezas, tarefas que requerem o uso do escrito.

Após apresentarmos as características da aprendizagem da escrita, insistindo nas especificidades do público adulto em face desse processo, questionaremos as abordagens de ensino de leitura-escrita para mostrar a importância, na formação de adultos, de não isolar as aprendizagens linguageiras e de apreender a escrita em sua complexidade e em sua inscrição sociocomunicacional.

\footnotetext{
${ }^{2}$ Distinguimos, especialmente na França, os públicos em situação de analfabetismo, que nunca foram escolarizados, crianças ou adultos (implicitamente, os que não tiveram nenhuma aprendizagem formal da língua escrita), dos públicos em situação de iletrismo, que efetuaram sua escolaridade obrigatória (até os 16 anos) ou parte dela, mas "não conseguem ler e compreender um texto sobre as situações de sua vida cotidiana, e/ou não conseguem escrever para transmitir informações simples (...)” (ANLCI, 2003).
} 


\section{Aprender ou (re)aprender a ler e a escrever na idade adulta}

\subsection{Pré-requisito e processo de aprendizagem do código escrito}

De modo a dar conta do que implica o fato de aprender ou de (re)aprender a escrita na idade adulta, fundamentamo-nos no estudo desse processo de aprendizagem tal como ele se desdobra na criança, por ser a literatura científica muito mais prolixa no que se refere ao público infantil. Partimos, portanto, desses trabalhos, evidenciando, particularmente, as considerações que nos parecem mais pertinentes para apreender a entrada no escrito pelos adultos. Acrescentemos que, por ser a literatura igualmente muito mais prolixa em relação à aprendizagem da leitura do que a da escrita, a entrada via "leitura" será central em nossa abordagem e o ponto de partida para mostrar as conexões necessárias com a aprendizagem da escrita.

Ao contrário de outras aprendizagens, a da escrita não se faz sem que se reflita sobre o próprio escrito, ou por simples imitação do adulto. Ela resulta da mobilização de capacidades reflexivas e linguageiras mais amplas. No plano linguageiro, vale lembrar de uma evidência: antes mesmo de ler ou escrever, a criança fala, assim como antes de falar uma língua, ela se comunica por meios vocais e gestuais. Aprendendo a escrita, a criança redescobre, assim, uma língua, cujo domínio oral ela já tem. Devemos à Emília Ferreiro (1977) o fato de ter evidenciado que a aprendizagem da escrita pela criança se faz de maneira progressiva (“evolução psicogenética") e repousa em uma apreensão cada vez mais fina das correspondências entre o código escrito que ela descobre e o código oral que ela, em parte, domina. Esse escoramento supõe, contudo, que a criança tenha conseguido se distanciar de seus usos da língua oral, de seus discursos, para analisar o que os compõem, as suas regras. A relação de familiaridade e proximidade que mantém com a língua deve, com efeito, dar lugar a um distanciamento suficiente para permitir a análise do funcionamento da linguagem. A esse respeito, nos anos de 1970, os estudos de Ferreiro mostram que, antes de sua entrada na escola primária, as crianças têm representações da escrita e de seu funcionamento muito distantes das convenções e dos usos desse código. Para elas, parece difícil compreender que todas as palavras pronunciadas oralmente possam ser escritas, ou ainda que a escrita represente as variações 
da forma sonora ${ }^{3}$. Para se preparar para aprender a ler e a escrever, a criança teria, então, necessidade de descobrir o universo da linguagem escrita, e mais especificamente, o código escrito. Essa descoberta ganha ao se apoiar nas aquisições linguageiras da criança e, portanto, em uma descoberta a partir do oral, dos sons e de suas combinações, de estratégias de comunicação, das palavras e de seus sentidos, dos agenciamentos sintáticos, dos textos e de suas funções (BENTOLILA et al., 1991). Downing e Fijalkow (1984) defendem, assim, a ideia de que as primeiras aquisições devem ser de ordem metalinguística, para assegurar a "clareza cognitiva" necessária à aprendizagem: a criança deve se conscientizar da natureza dos objetos que devem ser aprendidos para ser capaz de memorizar. E o fato de pôr em prática tarefas claras de análise da linguagem, fundamentando-se no que adquiriu por meio do oral, constituiria uma alavanca para a entrada no escrito.

Se essas competências metalinguísticas que parecem estar no fundamento da aquisição da leitura e da escrita foram muito estudadas nas crianças, poucas pesquisas foram consagradas aos processos mobilizados pelos adultos, a questão que se coloca sendo a de saber até que ponto as diferentes etapas de entrada no escrito são comuns às crianças e aos adultos. Evocamos brevemente algumas pesquisas sobre os adultos, centradas nos processos cognitivos de baixo nível, dos quais dão conta o artigo de Gombert e Largy (1995). Os autores, retomando alguns resultados de trabalhos anteriores, destacam que os adultos analfabetos encontram dificuldades em certos tipos de tarefa: a identificação de fonemas no início de uma palavra, a avaliação da extensão das palavras, a segmentação de frases orais em palavras, tarefas que são justamente o objeto das primeiras aprendizagens da leitura. A pesquisa realizada por Gombert e Largy, que compara as performances de sujeitos ditos "analfabetos", "semi-analfabetos" (seguindo uma formação em alfabetização) e "letrados", confirma que os adultos pouco ou não leitores são menos hábeis na realização desses três tipos de tarefas. A ausência ou a pouca consciência metalinguística nos sujeitos que nunca ou pouco aprenderam a ler e a escrever se explica pelo fato de que essas competências "meta-" não têm verdadeiramente utilidade fora da aprendizagem da leitura (GOMBERT E LARGY, 1995, p. 125). Por outro lado, parece que a capacidade para segmentar a linguagem oral pode perfeitamente ser adquirida na idade adulta por meio de práticas direcionadas a essa habilidade, e o estudo assinala fortemente os efeitos positivos sobre as performances da aprendizagem.

\footnotetext{
${ }^{3} C f$. Sprenger-Charolles (1989) para uma síntese dos trabalhos de Emília Ferreiro e de outros autores sobre as representações da escrita alfabética nas crianças.
}

Olh@res, Guarulhos, v. 4, n. 1, p. 107-124, maio 2016. 
Indo ao encontro dessas constatações, voltemos aos estudos referentes à aprendizagem pelas crianças, que consideram, com Bentolila et al. (1991), que, antes da e em paralelo à aprendizagem da leitura e da escrita, a criança deve desenvolver, por meio de um ensino adaptado, diferentes planos de consciência:

- A consciência comunicacional (compreender que uma mensagem escrita deve ser contextualizada em relação a uma situação particular de produção e que o emissor deve levar em conta o destinatário nela ausente);

- A consciência fônica (identificar os constituintes do oral);

- A consciência semiológica (reconhecer o código linguístico como um conjunto de signos arbitrários);

- A consciência lexical (tomar consciência, no nível do oral, do sentido dos lexemas em uso, para facilitar o trabalho de identificação do sentido das palavras que serão lidas);

- A consciência sintática (necessária para a identificação das relações que os diferentes segmentos de uma frase mantêm entre si);

- A consciência léxica (no sentido de Bentolila, é a descoberta pela criança do que significa ler, do que se pode ler, do que diferencia os diferentes tipos de escritos).

Para descrever o processo de aprendizagem da leitura, Golder e Gaonac'h (1998) retomam, dentre as múltiplas descrições do processo de aprendizagem da leitura, os trabalhos de Frith (1985), para identificar três fases. Na primeira fase, dita logográfica, a criança utiliza todos os índices, lhe permitindo o reconhecimento da palavra. Ela estabelece, assim, vínculos entre as configurações escritas (índices visuais) e a significação, tomando por apoio índices extralinguísticos extraídos do ambiente (cores, imagens, tipografia, traços visuais da palavra, etc.). Nessa etapa, a criança é capaz de identificar as palavras (nas publicidades ou produtos de consumo cotidiano, por exemplo) sem que seus constituintes sejam identificados e relacionados com seus correspondentes fônicos. Ao longo da segunda fase, alfabética, a criança - aprendiz de um sistema de escrita alfabética - vai estabelecer correspondências entre o escrito e o oral, utilizando a mediação fonológica para decodificar as palavras. Ela se apoia, assim, em sua capacidade de segmentar a cadeia falada em unidades menores de som (sílabas, fonemas) para ler letras ou sequências de letras e estabelecer analogias entre as palavras ("mamy começa como mamãe", por exemplo). Por fim, na terceira fase, fase ortográfica, as palavras vão ser analisadas em unidades ortográficas sem passagem sistemática pelo oral (conversão 
fonológica). A criança utiliza do procedimento dito de acesso direto para reconhecer a palavra, sem, contudo, encontrar-se em um reconhecimento global (como na fase logográfica), mas recorrendo à identificação de unidades ortográficas (grupos de letras) combinadas nas palavras.

Defendendo a ideia de uma interdependência entre leitura e escrita, Golder e Gaonac'h assinalam que, na passagem de uma fase de aprendizagem da leitura à outra, a escrita pode desempenhar um grande papel. Copiando, por exemplo, as palavras que acaba de aprender a ler, uma criança pode começar a formar uma representação ortográfica. Para escrever, ela analisa, decompõe a palavra e começa, assim, a apreender a sequência de letras ordenadas que a constitui, o que é próprio a ajudá-la a deixar para trás a etapa logográfica. A escrita impõe, dessa forma, uma exigência na correspondência grafofonológica que pode sustentar a aprendizagem da leitura. Para escrever uma palavra nova ou ao menos uma palavra sem representação ortográfica para o escritor, é necessário se basear em outros índices e, portanto, proceder a uma análise dessa palavra em fonemas, que serão posteriormente convertidos em unidades gráficas (MORAIS, 1994). A escrita alfabética vai alimentar o processo de leitura alfabética, enquanto que o processo ortográfico vai, antes, se desenvolver essencialmente na leitura (para uma leitura mais precisa e mais rápida), para, depois, se transferir para a escrita, permitindo ao aluno escrever todas as palavras.

As duas habilidades (leitura-escrita) sustentam-se uma à outra e funcionam como estimuladores para um desenvolvimento mútuo das competências necessárias ao cumprimento de tarefas de leitura e escrita (SPRENGER-CHAROLLES \& CASALIS, 1996). Essa imbricação dos processos se encontra nas altas correlações existentes entre as capacidades de leitura e as de escrita (GOLDER \& GAONAC'H, 1998). Para fechar essa retomada sintética a respeito da aprendizagem do código escrito, lembremos que o desenrolar desse processo e as atitudes da criança face à escrita estão fortemente correlacionados a fatores externos e particularmente ao lugar ocupado pelo letramento no ambiente cotidiano da criança e à relação que mantém com a sua família (hábitos de leitura, valorização da escrita etc.) (BOUVET; FALAIZE \& FREYNET, 1995).

\subsection{Representações, práticas sociais e culturais da escrita: relação com a aprendizagem}

O percurso seguido pelas crianças, no âmbito da escolarização obrigatória, é de natureza a fazer evoluir a relação que elas mantêm com a escrita. Ele suscita o 
desenvolvimento de novas representações sobre a linguagem em geral e sobre a escrita em particular, permitindo o desenvolvimento de novas capacidades linguageiras, a emergência de novos usos. Contudo, uma parte desses alunos custa a estabelecer uma sólida relação com a escrita e a adquirir competências suficientes para assegurar o seu sucesso escolar. Instala-se, então, muito cedo, uma relação penosa para com a escola e os letramentos escolares, isso já desde os primeiros anos da escola obrigatória (GIASSON, 2012), pois o fracasso na leitura repercute no conjunto das disciplinas escolares que são massivamente mediadas pela língua escrita.

É uma experiência escolar dolorosa, uma imagem de si desvalorizada e uma falta de confiança em suas capacidades, uma representação negativa e errônea das aprendizagens, ou ainda, representações de usos da língua mais legítimos do que outros, que frequentemente caracterizam os adultos em situação de iletrismo, e que devem ser considerados pelo formador (TORUNCZYK, 2013). A situação dos analfabetos, tal como é descrita por Torunczyk em sua experiência como formadora, é sensivelmente diferente: se a falta de escolarização ou a sua interrupção precoce podem ser vividas com lamento ou ressentimento, a imagem de si não é atingida pela repetição do sentimento de fracasso. Ela parece muito mais desencadear uma motivação maior para se lançar nas aprendizagens da escrita, que está associada a uma confiança na possibilidade de mudar de vida. Percebemos o quanto, nesses dois perfis de aprendizagem, as aprendizagens dos adultos fundamentam-se em aquisições e representações amplamente diferentes daquelas das crianças.

Com efeito, é preciso assinalar o peso do que vem com a experiência e o lugar a lhe ser destinado na formação, nas articulações a serem feitas com os conteúdos de formação, em uma perspectiva de valorização do já adquirido. Os trabalhos se interessam, assim, pelas aprendizagens ao longo da vida, e, a esse respeito, pelos saberes e savoirfaire adquiridos em letramento ou em outros domínios fora da escola obrigatória e formações de qualificação. Nesse âmbito, a noção de "aprendizagem informal" designa, portanto, frequentemente, o que se aprende em situação de trabalho, na ação, ou em qualquer outra situação da vida cotidiana em que se tem um problema a ser resolvido (BÉLISLE, 2012) e se mobilizam a leitura ou a escrita para realizar tarefas.

Mesmo considerando que alguns adultos em formação ainda não tenham sido alfabetizados, na sociedade que os acolhe, por conta de suas atividades sociais cotidianas, eles são confrontados permanentemente à escrita, construindo, a respeito desse código e 
desse universo, representações sociais e aquisições que vão ter uma incidência sobre o seu processo de aprendizagem.

As representações suscetíveis de ter um impacto na formação se relacionam notadamente à língua escrita e à própria situação de aprendizagem.

Tratando-se das representações da escrita, as análises de Torunczyk (2013), referentes tanto aos públicos ditos "iletrados" quanto aos ditos "analfabetos", confirmam, essencialmente, os resultados das pesquisas realizadas nos anos de 1990, por exemplo, Bourgain (1992) ou Dabène (1987), sobre as representações da língua escrita e da norma nos adultos em situação de insegurança escritural. Para os aprendizes em situação de iletrismo, as representações são marcadas pelo peso de uma norma escritural que classifica e desclassifica os sujeitos, conforme a adequação de suas produções às expectativas sociais. A esse respeito, a norma ortográfica ocupa um lugar central nas representações da competência escritural das pessoas entrevistadas nas pesquisas, e isso em detrimento de outras dimensões menos locais, mas igualmente importantes, tais como a organização dos textos, a conformidade aos gêneros de escrita ou os ajustamentos de ordem sociolinguística dos produtos escritos. Resulta daí uma visão redutora das dificuldades encontradas pelos escritores pouco escolarizados, para os quais "escrever bem" pode significar "bem formar suas letras" e "ter uma boa ortografia" (BOURGAIN, op. cit.). Os aprendizes não escolarizados tendem, eles também, a associar a língua escrita à língua socialmente legítima, mas, a essa percepção, pode se acrescentar um fenômeno de desvalorização de sua língua de origem (TORUNCZYK, op. cit.).

Do lado das representações da aprendizagem, as dos adultos "iletrados" são herdadas de experiências escolares infelizes, e os discursos dos aprendizes entrevistados remetem de maneira recorrente a um modelo de aprendizagem escolar da escrita centrado nas atividades de memorização/repetição/aplicação. Este modelo é, ademais, associado às dimensões emocionais, em particular, de angústia, que correspondem aos sentimentos do que é penoso, do quão absurdas são as atividades, a uma ansiedade em relação às situações de avaliação, bem como à exposição de suas dificuldades para os outros (Le FERREC, 2003).

Os aprendizes pouco ou não escolarizados têm, por sua vez, frequentemente uma visão escolar tradicional, herdada de um modelo transmissivo de ensino (o professor transmite seus saberes ao aluno que os recebe passivamente). Por outro lado, o trabalho com o oral é percebido como inútil e vivido como uma perda de tempo, na medida em 
que o código escrito tem tendência a ser percebido como desprovido de ligação com o oral (ADAMI, 2009).

Um dos desafios da formação linguística é também, portanto, o de conceber condutas pedagógicas que permitam fazer evoluir essas representações da língua escrita, de seu funcionamento e das aprendizagens, na medida em que tais representações podem constituir um freio para as aprendizagens em si.

Outra dimensão das aprendizagens que deve ser igualmente levada em consideração é a que diz respeito ao "aprender a aprender", ou seja, aos comportamentos metacognitivos. Ocorre que formadores iniciantes ou pouco formados nas especificidades dos públicos não escolarizados subscrevem à hipótese de um déficit cognitivo quando certas atividades fazem com que esses adultos em formação fracassem. Como assinala Adami (2009, p. 59), “(...) os analfabetos não têm dificuldades para aprender a ler porque eles teriam um problema de ordem cognitiva ou de "raciocínio", mas eles têm problemas de raciocínio porque eles não sabem ler e escrever". É de fato na escola que os alunos são conduzidos a realizar determinadas operações de pensamento nas atividades de leitura e escrita e a se familiarizar com alguns tipos de exercício e atividade. Não é uma surpresa que adultos não compreendam imediatamente o que significa uma dada orientação como “assinalar" ou "relacionar" em exercícios de correlação, ou o funcionamento de tabela de entrada dupla, ou ainda que penem para organizar e classificar os documentos distribuídos em aula. São precisamente capacidades e competências decorrentes do que Goody (1979) chama de "razão gráfica".

Resulta desses alguns poucos elementos a necessidade de distinguir os perfis de públicos em formação a partir do critério da escolarização e das aprendizagens formais da escrita e do estatuto da língua-alvo para o aprendiz (língua materna ou estrangeira), para construir percursos de aprendizagem adaptados. Por outro lado, essas (re)aprendizagens se inscrevem nos percursos de vida, das experiências linguageiras, sociais, profissionais e, consequentemente, das aquisições de toda natureza sobre as quais a formação linguística terá todo interesse em se apoiar.

\section{Ensinar a leitura e a escrita aos adultos: quais orientações didáticas?}

\subsection{Algumas referências transversais sobre os métodos} de ensino de leitura e escrita

É comum distinguir, em didática da leitura-escrita, três grandes tipos de abordagem, conforme as unidades e as habilidades tomadas como ponto de partida e 
consideradas como centrais no ensino. Essas abordagens, implementadas tanto com as crianças quanto os adultos, têm sua origem, ao mesmo tempo, em correntes didáticas, nas teorias linguísticas e nos modelos de leitura, desenvolvidos particularmente em psicologia cognitiva e em psicolinguística. Esses modelos propõem uma identificação e uma hierarquização dos fatores implicados no processo de elaboração do sentido na escrita (ECALLE \& MAGNAN, 2002). Eles são essencialmente elaborados, como lembram Cornaire e Germain (1999), a partir de estudos descritivos ou experimentais sobre a leitura em língua materna (no sistema alfabético) para crianças e podem ser fragmentados em três tipos: modelos bottom-up, ou ascendentes, modelos top-down, ou descendentes, e modelos interativos. São essas mesmas três entradas que encontramos, na França, de forma recorrente na designação das abordagens didáticas: por um lado, métodos ditos silábicos ou ainda fônicos (entrada fonêmica ou grafêmica), sintéticos; por outro, métodos apreendidos como globais, ou, mais especificamente, ideovisuais, whole language e, por fim, métodos ditos interativos ou integrativos ${ }^{4}$. Esses últimos se opõem aos outros, que podem ser qualificados como modelos autônomos, pelo fato de considerarem influências diretas entre os processos de tratamento contextual (alto nível) e os processos de tratamento gráfico (baixo nível) (GOIGOUX, 1991).

Antes de detalhar a metodologia interativa na qual inscrevemos nosso propósito, lembremos em poucas palavras as grandes linhas dos dois outros tipos de métodos.

Esses dois modelos (bottom-up e top-down), como propõe Chauveau (2007), podem, antes de tudo ser situados nos dois extremos de um continuum, conforme a uma unidade linguística privilegiada que é menor e vinculada à forma, ao código (os sons, as letras, as palavras) nos métodos ascendentes ou, ao contrário, maior e global (o texto) nos métodos descendentes. O princípio dos métodos descendentes é o de partir do sentido e do todo, considerando que a compreensão é um processo contínuo de elaboração e de verificação de hipóteses emitidas pelo aprendiz-leitor, a partir de sua experiência e seus conhecimentos, do contexto da escrita e do levantamento de índices no próprio texto. A leitura e a escrita são, então, apreendidas como meios de comunicação e processos "naturais". Nessa lógica, consideramos que o aprendiz constrói seus conhecimentos em um procedimento indutivo, por confronto direto com as atividades de comunicação escrita. Os aprendizes são, portanto, colocados no centro da construção dos saberes e o

\footnotetext{
${ }^{4}$ Para uma síntese desses modelos e métodos, ver particularmente Cornaire e Germain (1999), Chauveau (2007), Leclercq (1999) e Morais (1994).
}

Olh@res, Guarulhos, v. 4, n. 1, p. 107-124, maio 2016. 
ensino não se baseia em ferramentas didáticas préconstruídas, propondo uma progressão pré-estabelecida que iria do simples ao complexo.

Inversamente, as abordagens ascendentes partem do princípio de que a significação de um texto se constrói, no ato da leitura, a partir da codificação de unidades de bases menores para as maiores, passando, portanto, pela identificação das letras, das sílabas, das palavras e, em seguida, pela compreensão das frases e relações interfrásticas no âmbito do texto. A interpretação do texto basear-se-ia, portanto, na justaposição dos elementos sucessivamente identificados em uma ordem hierárquica. $\mathrm{O}$ ensino vai então consistir, numa lógica linear, em transmitir, antes, conhecimentos simples (os que recaem sobre as pequenas unidades: letras/sons, sílabas), depois conhecimentos mais complexos relativos às unidades maiores (texto). A progressão é pensada pelo professor, deixando pouco espaço para uma intervenção do aprendiz, enquanto a aprendizagem do código, especialmente das regularidades grafo-fonológicas, é considerada como central. Sem essa base, a identificação das palavras não se mostra possível.

Além disso, cada um desses tipos de métodos não confere a mesma importância à cultura escrita no processo de ensino-aprendizagem. A focalização do código nos métodos ascendentes limita a consideração das dimensões culturais que implicariam, de fato, uma forte contextualização do trabalho sobre a escrita. Ao contrário, a abordagem descendente dos textos em sua globalidade e ao sabor das situações de comunicação escrita permite uma forte contextualização do trabalho sobre a escrita e a confrontação do aprendiz a uma diversidade de escritos, podendo favorecer o enriquecimento de sua cultura escrita. Há, sob essa ótica, um ponto comum entre os métodos ditos globais e os métodos interativos dos quais vamos agora tratar. Com efeito, os modelos interativos conferem uma importância particular ao contexto no qual os atos de leitura-escrita se inscrevem, ao considerar que a confrontação aos contextos socioculturais variados e, portanto, a uma diversidade de escritos permitiria alimentar o processo de aprendizagem, fornecendo ao aprendiz a possibilidade, graças à mediação do professor, de pôr em prática atividades cognitivas diversificadas.

Do ponto de vista da atenção dedicada ao código, os modelos interativos, hoje amplamente dominantes, teoricamente como empiricamente nas práticas de ensino contemporâneas, tentam, de alguma maneira e sob diversas formas, uma reconciliação entre os dois modelos extremos do continuum anteriormente apresentados. E isso ao considerarem as interações possíveis entre os tratamentos de nível superior e os de nível inferior. Assim, ao apontar o que se tem em termos de ensino da leitura na Europa, a 
comissão europeia (EURYDICE; EACEA, 2011) mostra que esse ensino, tal como é preconizado nos sistemas educativos europeus, comporta esquematicamente três eixos complementares: "o desenvolvimento dos fundamentos da aquisição da leitura (consciência fonêmica, consciência do escrito); o ensino das bases da leitura (focalizado no reconhecimento das palavras, na utilização das correspondências grafema-fonema e fluidez) e o ensino de estratégias de compreensão para a leitura" (p. 53). O ensino dessas estratégias de compreensão consiste, especialmente, em favorecer a utilização dos conhecimentos contextuais, em estabelecer vínculos entre as diferentes partes de um texto. $\mathrm{O}$ ato de leitura é concebido então, ao mesmo tempo, como baseado na decodificação e na implementação de estratégias de compreensão.

Seguindo essa orientação, gostaríamos, agora, de mostrar o interesse que existe, na formação de adultos, em não separar as aprendizagens linguageiras (de um lado oral/escrito, de outro, leitura/escrita) e trabalhar as inter-relações entre os diferentes níveis de tratamento da escrita para desenvolver as capacidades do aprendiz (leitor/escritor) em adaptar suas condutas e estratégias à tarefa de compreensão ou produção na qual está implicado.

\subsection{Para além da aprendizagem do código: quais dimensões integrar no ensino da escrita?}

Consideremos, aqui, duas dimensões: o lugar do oral no processo de entrada dos adultos no escrito e o desenvolvimento de competências extralinguísticas associadas à aprendizagem do código. A escolha dessas dimensões é guiada pela constatação que nossas experiências de formadoras de formadores e nossos trabalhos anteriores (MANESSE et al., 2014; AUZANNEAU \& LECLÈRE, 2009) nos permitem traçar quanto às representações da língua escrita subjacentes às práticas de ensino da escrita aos adultos. As práticas, observadas ou verbalizadas, dos formadores (mais ou menos experientes) mostram, com efeito, que uma abordagem da língua escrita demasiadamente centrada no código (independentemente de seus usos para fins comunicacionais e do modo como se apresentam) e focalizada em suas especificidades (ao invés de relacionála com a língua oral) pode conduzir a uma análise altamente parcial das competências e necessidades dos aprendizes, bem como a uma delimitação insatisfatória dos objetivos e dos procedimentos de ensino.

\subsubsection{Lugar do oral no ensino da escrita aos adultos}

Olh@res, Guarulhos, v. 4, n. 1, p. 107-124, maio 2016. 
Nas seções anteriores, mostramos a importância de se pôr em correlação, as unidades do oral às unidades gráficas no processo de aprendizagem da leitura, especialmente em suas primeiras etapas. $\mathrm{O}$ exame das performances em leitura-escrita de adultos mostra, como relatam Eme et al. (2011), que as pessoas em situação de iletrismo recorrem a estratégias pouco eficazes, que impedem, sobretudo, as novas aquisições. São pontuadas, em particular, a decodificação monótona trabalhosa, a ausência de busca pelo sentido e mais globalmente a dificuldade de serem estabelecidos vínculos entre o oral e o escrito. Comparadas às das crianças em um mesmo nível de leitura, o tratamento das palavras por esses adultos parece ser específico. Eles sentem mais dificuldades na utilização dos procedimentos fonológicos do que dos ortográficos para identificar as palavras escritas. Isso se traduziria em um déficit no tratamento fonológico das palavras escritas e entravaria sua progressão na leitura-escrita, ainda que esses adultos apresentem boas capacidades de compreensão da linguagem oral.

Percebemos, assim, o interesse que existe em não se negligenciar, no ensino da escrita, o trabalho com o oral e, mais especificamente, o desenvolvimento da consciência fonológica (conhecimento das propriedades fonológicas da linguagem), da consciência fonêmica (identificação dos fonemas constitutivos das palavras) e do sistema fonológico do aprendiz. Essas capacidades são necessárias para um bom pareamento entre signos gráficos e fonemas (decodificação grafo-fonética) e para alcançar, na leitura, uma boa identificação-compreensão das palavras, e, na escrita, uma boa ortografia (cf. EURYDICE, 2011). E essa etapa dita de montagem (fazer corresponder letras e sons) é crucial, na medida em que sua automatização constitui uma alavanca para uma identificação rápida das palavras e a criação de referências ortográficas estáveis. O léxico mental do leitor (associação direta entre forma ortográfica e sentido) se constitui assim progressivamente e a montagem automatizada permite a leitura e a memorização de palavras raras ou novas que ainda não estariam no léxico mental. O domínio da linguagem oral constitui, de diversas maneiras, um recurso fundamental para a aprendizagem e o desenvolvimento das competências escritas. $\mathrm{O}$ recurso ao contexto mencionado, como recorrente nas estratégias de leitura dos adultos em situação de iletrismo, como os conhecimentos lexicais, podem, com efeito, vir a sustentar, confirmar o trabalho de decodificação e facilitar o acesso ao sentido.

Para o aprendiz que entra no escrito por uma língua que não é a sua primeira, ou que ele não domina oralmente, o desafio de um ensino que deixe um espaço de escolha ao oral é ainda mais importante. Sem conhecimento mínimo da língua oral, sem 
consciência fonêmica e sem domínio do sistema fonológico, o aprendiz não poderá ter acesso a uma identificação rápida e automatizada das palavras. Ele consagrará, então, muitos dos recursos cognitivos a esse nível de tratamento do escrito em detrimento dos outros (sintático, semântico, textual).

Mais amplamente, um trabalho com a linguagem oral na formação na escrita dos adultos é de natureza a permitir um enriquecimento de competências sintáticas, discursivas, mas também metalinguísticas e pragmáticas conjuntamente mobilizáveis nos atos de leitura-escrita. Esse enriquecimento pode se fundamentar, na formação, na aplicação de atividades confrontando o aprendiz aos diferentes discursos por sua forma, situações nas quais se inscrevem, por seu caráter mais ou menos literal, por seu grau de abstração. O aprendiz, guiado pelo formador, desenvolverá sua capacidade de manejo e de análise da linguagem oral em situação. Por esse tipo de abordagem, implementada no oral, pode-se, ademais, desenvolver a competência comunicacional fazendo com que o aprendiz perceba o quanto a construção do sentido (em produção ou em compreensão) repousa na consideração de um grande número de índices linguísticos (as palavras escolhidas, seu agenciamento, as marcas de coerência etc.), mas também de índices para ou extralinguísticos (os interlocutores presentes, o quadro espaço-temporal, as finalidade da troca, as entonações, os gestos etc.). Ora, essas dimensões estão em grande parte presentes no escrito e podem constituir recursos não negligenciáveis para aceder ao sentido de um texto ou ajustar sua produção escrita.

\subsubsection{Lugar das dimensões extralinguísticas no desenvolvimento das competências em leitura-escrita}

Se o ensino da escrita aos adultos iniciantes se limita a um trabalho sobre o código (as unidades fonéticas, lexicais, sintáticas e seu agenciamento), o risco de saída é que o aprendiz não capte a função primeira desse código, a de comunicar, e que, em seguida, se veja em dificuldade para, em situação, recorrer habilmente ao código, a fim de satisfazer as intenções de comunicação. O segundo risco é que ele integre a ideia de que o sentido só se constrói pelo código e que se prive, assim, de levar em consideração outros índices que são, contudo, significativos para a escrita. Aceder ao sentido de um documento escrito é, de fato, aceder ao sentido das palavras pela decodificação das unidades, mas isso se fundamenta igualmente no tratamento de índices de ordem extralinguística: informações tipográficas e referentes à disposição, tais como as variações de fonte e caixa 
(maiúsculo/minúsculo), o espaçamento entre linhas, as margens, as imagens, a relação texto-imagem, a disposição das informações umas em relação às outras (em lista ou em tabela, por exemplo). Informações dessa natureza, se abordadas, permitirão ao leitor distinguir, por exemplo, um cartaz de cinema de uma fatura, ou ainda de um romance, ou de uma história em quadrinhos. Se esses índices não são mais levados em conta pelo leitor, o trabalho que ele terá que fazer sobre os conteúdos linguísticos corre o risco de ser mais custoso no plano cognitivo (particularmente na leitura de textos não lineares, diante dos quais a boa estratégia não é a de se focalizar sobre as palavras, mas a de olhar, antes, o escrito em sua globalidade). Considerar os elementos não linguísticos cria, com efeito, um horizonte de expectativas, e permite inscrever o trabalho de construção do sentido em um quadro mais delimitado. Na formação, a familiarização com diferentes tipos de documentos escritos pode ensinar a se localizar em um suporte e a se sensibilizar às diferentes disposições gráficas (tabela, texto, lista, carta, plano, calendário). Além disso, esse tipo de abordagem permite valorizar as experiências e aquisições dos aprendizes que frequentemente já sabem reconhecer determinados tipos de escritos.

Correlativamente, nas tarefas de escrita, o aprendiz deve descobrir que, para além da convenção (sentido e direção de escrita), o agenciamento das palavras e dos segmentos de texto sobre a folha, em numerosas situações, é determinado por normas sociolinguísticas que fazem com que, por exemplo, uma carta formal, se não satisfizer essas normas, corre o risco de não ser bem recebida por seu destinatário e de perder seu objetivo. De questões tipográficas e de disposição, deslizamos, assim, em direção às dimensões pragmáticas e socioculturais.

Se, como já destacamos, a leitura e a escrita são processos de comunicação social e interindividual, há então uma pertinência que o trabalho sobre a escrita não se faça de modo descontextualizado, mas, ao contrário, esteja socialmente ancorado. Escreve-se para informar, contar, explicar, protestar, para uma ou mais pessoas, em situações sociais singulares. A essas funções e essa inscrição social da escrita, os adultos aprendizes já se confrontaram em seu cotidiano (ainda que nem sempre tenham consciência disso). O trabalho do formador é, então, referindo-se às experiências dos aprendizes e propondo documentos autênticos, com funções diversas e oriundos de contextos de utilização específicos (a família, a escola, a administração, os comércios, a cultura...), o de propor atividades, com vistas ao desenvolvimento da consciência e das habilidades comunicacionais. 


\section{Conclusão}

As abordagens convocadas no decorrer desse artigo mostram, em sua complementaridade, que a entrada no escrito na idade adulta repousa em múltiplos parâmetros, devidos, em partes, ao desenvolvimento das capacidades cognitivas e linguísticas, mas que repousam igualmente em uma reflexão relativa às experiências de escrituralidade e sua inscrição sociocomunicacional.

As especificidades do código escrito requerem, para o domínio da leitura e da escrita, o desenvolvimento e a mobilização de condutas que apenas o domínio do oral, em seus usos cotidianos, não pode garantir. Porém, à luz dos trabalhos em psicolinguística, nota-se que a aprendizagem da língua escrita se baseia amplamente nas competências já desenvolvidas no oral, na medida em que ninguém pode aprender a ler em uma língua que lhe é totalmente desconhecida. Um domínio mínimo do oral constituiria, então, um pré-requisito para a aprendizagem da escrita, mas só poderia funcionar como o que impulsiona essa aprendizagem se é oferecido ao aprendiz um meio de se distanciar de seus usos da língua oral para tomar consciência de seus componentes linguísticos e comunicacionais.

Paralelamente a isso e para além do código, as representações e as experiências sociais que os aprendizes têm do escrito impregnam necessariamente suas estratégias e as condutas implementadas, seja em seus usos sociais ou em suas práticas de aprendizagem. Sua entrada no escrito se inscreve em uma dinâmica mais global, tanto no plano de seu percurso individual de leitor-escritor, quanto de suas práticas e necessidades sociais relativas à escrita.

O trabalho do formador se situa em uma conciliação entre esses diferentes desafios para favorecer o desenvolvimento de saberes, e, sobretudo, de savoir-faire, permitindo ao leitor-escritor em formação realizar tarefas escritas variadas, solicitadas em sua vida social e profissional. Coloca-se, assim, a pergunta de saber como, na prática, os formadores articulam as diferentes dimensões implicadas na aprendizagem da escrita pelos adultos, ao mesmo tempo em que lidam com fortes restrições situacionais e, particularmente, com uma grande heterogeneidade dos públicos adultos, em formação. A pesquisa, ainda um pouco prolixa sobre esse assunto, teria muito a ganhar com um melhor conhecimento da criatividade posta em jogo pelos formadores para enfrentá-la. 


\section{REFERÊNCIAS BIBLIOGRÁFICAS}

ADAMI, H. La formation linguistique des migrants. Paris: Clé International, 2009.

AGENCE NATIONALE DE LUTTE CONTRE L'ILLETTRISME - ANLCI. Cadre national de référence. Lyon, 2003

AUZANNEAU, M.; LECLÈRE-MESSEBEL, M. L'enseignement/apprentissage du français dans la formation pour adultes : questionnements sociolinguistiques. In: PIEROZAK, I.; ELOY, J. M. (dir.) Intervenir : appliquer, s'impliquer? Paris: L'Harmattan, 2009, p. 227-232.

BAUTIER, E. Quand le discours pédagogique entrave la construction des usages littéraciés du langage. In: Pratiques, n. 143/144, 2009, p. 11-26.

BENTOLILA, A.; CHEVALIER, B.; FALCOZ-VIGNE, D. La lecture, apprentissage, évaluation, perfectionnement. Paris: Nathan, 1991, p. 192-197.

BELISLE, R. (2012), Ecrire, lire et apprendre à l'âge adulte. Laval: Presses universitaires de Laval.

BOURGAIN, D. Normes et écritures. De quelques représentations recueillies auprès de personnels dits de "basse qualification". In: BESSE J.-M.; De GAULMYN, M.; GINET, D.; LAHIRE, B. (Eds.) L'« illettrisme » en questions. Cahiers du PsyEF, 2, Lyon: PUL, 1992, p. 163-179.

BOUVET, C.; FALAIZE, B.; FEDERINI, F.; FREYNET, P. L'illettrisme : une question d'actualité. Paris: Hachette, 1995.

CHAUVEAU, G. Le savoir-lire aujourd'hui. Paris: Retz, 2007.

CORNAIRE, C.; GERMAIN, C. Le point sur la lecture. Paris: Clé International, 1999.

DABÈNE, M. L'adulte et l'écriture. Contribution à une didactique de l'écrit en langue maternelle. Bruxelles: De Boeck Université, 1987.

DOWNING, J.; FIJALKOW, J. Lire et raisonner. Toulouse: Privat, 1984.

EURYDICE; EACEA L'enseignement de la lecture en Europe : contextes, politiques et pratiques, Bruxelles: [s.n], 2011.

ECALLE, J.; MAGNAN, A. L'apprentissage de la lecture. Fonctionnement et développement cognitifs. Paris: A. Colin, 2002.

EME, E.; NANTES, N.; DELLIAUX, C. Analyse cognitive et linguistique de l'illettrisme: bilan des études et implications pour la formation. In: L'orientation scolaire et professionnelle, 40/3, 2011. Disponível em: 〈http://osp.revues.org/3516>. Acesso em: 15 fev. 2016.

FERREIRO, E. Vers une théorie génétique de l'apprentissage de la lecture. In: Revue suisse de psychologie. [S.1.], 36, 1977, p.109-130. 
FRITH, U. Beneath the surface of developmental dyslexia. In: K. Patterson; J. Marshall; M. Coltheart. (Eds.) Surface Dyslexia, Neuropsychological and Cognitive Studies of Phonological Reading. London: Erlbaum, 1985, p. 301-330.

GIASSON, J. La lecture. Apprentissage et difficultés. Bruxelles: De Boeck, 2012.

GOIGOUX, R. Les 5-8 ans et les modèles interactifs. La lecture au cycle des apprentissages. In: BENTOLILA, A. La lecture: apprentissage, évaluation, perfectionnement. Paris: Nathan, 1991, p. 192-197.

GOLDER, C.; GAONAC'H, D. Lire et comprendre: psychologie de la lecture. Paris: Hachette, 1998.

GOMBERT, J.-E.; LARGY, F. Acquisitions métalinguistiques chez les analphabètes. In CALAP, $n^{\circ} 13,1995$, p. 123-143.

GOODY, J. La raison graphique. La domestication de la pensée sauvage, Paris: Les Editions de minuit, 1979.

LECLERCQ, V. Face à l'illettrisme: Enseigner l'écrit à des adultes. Paris: ESF, 1999.

LE FERREC, L. Les représentations de l'écrit chez les adultes en situation d'illettrisme : un obstacle à l'acculturation à l'écrit en formation de base? Mémoire de Diplôme d'Etudes Approfondies en Didactique des langues et des cultures, sous la direction de Jean-Louis Chiss, Université Paris 3-Sorbonne Nouvelle, 2003.

MANESSE, D. et al. Enseigner aux publics faiblement lettrés : savoirs académiques face aux savoirs d'expérience, Paris: USPC, 2014.

MORAIS, J. L’art de lire. Paris: Odile Jacob, 1994.

SPRENGER-CHAROLLES, L. ; CASALIS, S. Lire. Lecture/écriture: acquisition et troubles du développement, Paris: PUF, 1996.

SPRENGER-CHAROLLES, L. Note de synthèse - L'apprentissage de la lecture et ses difficultés. Approche psycholinguistique. Revue française de pédagogie, v. 87, 1989, p. 77-106. Disponível em: <http://www.persee.fr/doc/rfp_05567807_1989_num_87_1_1422>. Acesso em: 15 fev. 2016.

TORUNCZYK A.Représentations de l'écrit et image de soi : les obstacles à l'apprentissage. Un retour sur expérience. Cahiers de la recherche sur l'éducation et les savoirs. Dez. 2013. Disponível em: 〈http://cres.revues.org/2393〉. Acesso em: 15 mar. 2016.

Recebido em: 05/04/2016

Aprovado em: 22/05/2016 